\title{
Association of Body Mass Index with Semen Quality and Sexual Hormone Levels among Men in Intrauterine Insemination
}

\author{
Erhong Zhang1, Hui Zhang2, Zhijun Zang', Jun Chen', Bin Zhang ${ }^{*}$ \\ ${ }^{1}$ Department of Infertility and Sexual Medicine, The Third Affiliated Hospital of Sun Yat-sen University, \\ Guangzhou, China \\ ${ }^{2}$ Department of Ultrasound, The Third Affiliated Hospital of Sun Yat-sen University, Guangzhou, China \\ Email: ${ }^{\text {doctorzb@163.com }}$
}

Received 26 May 2014; revised 9 July 2014; accepted 20 July 2014

Copyright (C) 2014 by authors and Scientific Research Publishing Inc.

This work is licensed under the Creative Commons Attribution International License (CC BY). http://creativecommons.org/licenses/by/4.0/

(c) (i) Open Access

\begin{abstract}
Background: The available evidence on the role of obesity and BMI on male infertility has been controversial or inconclusive to some extent. Objectives: To investigate the role of BMI on semen quality and hormone levels in men received intrauterine insemination. Material and Methods: A total of 390 males seeking artificial insemination in our department were recruited. BMI, blood pressure and semen parameters were assessed. Morning blood sample was taken for serum levels of testosterone (T), prolactin (PRL), luteinizing hormone (LH), follicle stimulating hormone (FSH), and estradiol $\left(E_{2}\right)$. Results: Subjects were divided into four groups according to BMI. There was no significant difference among groups in any of semen parameters and serum levels of FSH, LH, PRL and $E_{2}$. Obese and overweight men were found having lower serum levels of $T$ and higher levels of $E_{2} / T$ ratio than those of normal and underweight men. BMI was not found to be associated with semen parameters. Conclusion: This study has not found evidence of an association between BMI and semen parameters, but obesity has a negative effect on serum testosterone levels.
\end{abstract}

\section{Keywords}

Body Mass Index, Obesity, Semen, Sexual Hormone

\section{Introduction}

Subfertility affects at least $10 \%$ of the population in the developed world [1]. Assisted reproductive technology,

*Corresponding author.

How to cite this paper: Zhang, E.H., Zhang, H., Zang, Z.J., Chen, J. and Zhang, B. (2014) Association of Body Mass Index with Semen Quality and Sexual Hormone Levels among Men in Intrauterine Insemination. Health, 6, 1861-1865.

http://dx.doi.org/10.4236/health.2014.614218 
such as artificial insemination with husband sperm, is able to treat couples with fertility problems, especially for infertile men [2]. The interaction between obesity and fertility has received increased attention owing to the rapid increase in the prevalence of obesity in the developed world. Some studies reported that obesity not only related to health problems like diabetes, hypertension, and sexual hormonal status, but also related to reproductive problems [3]-[5]. Obese men exhibit poor sperm quality, reduced androgen levels, elevated estradiol levels and reduced inhibin B correlating with the degree of obesity [6] [7]. On the other hand, some studies reported that there was no significant correlation between body mass index (BMI) and semen or hormonal parameters [8] [9].

The available evidence on the role of obesity and BMI on male infertility has been controversial or inconclusive to some extent. We hypothesized that BMI was inversely correlated with fertility, manifested by reduced semen concentration and serum levels of testosterone. The aim of this study was to investigate the effect of BMI on semen quality and sexual hormone levels in infertile men.

\section{Material and Methods}

This is a retrospective study conducted at department of infertility and sexual medicine from February 2009 to February 2012. Infertility is defined by World Health Organization as the failure of a couple to conceive a pregnancy following 12 months of unprotected intercourse [10]. A total of 390 males seeking artificial insemination with husband sperm (AIH) in our department were recruited. The study was approved by the reproductive medicine ethics committee of our hospital. Written informed consent was obtained from participating patient.

Subjects were exposed to medical history evaluation as well as physical and systemic examination. Exclusion criteria included apparent genital infection, uncontrolled hypertension, and azoospermia. Because patients with total progressive sperm under 5 million were advised to accept intracytoplasmic sperm injection (ICSI) treatment, most of these patients accepted ICSI and not included in this study. Total progressive sperm count $\left(10^{6} /\right.$ ejaculate $)=$ Total sperm count $\left(10^{6} /\right.$ ejaculate $) *$ sperm activity $(\%)$. BMI was calculated as the weight in kilograms divided by the square of height in meters. The participants were divided into four groups based on BMI $\left(<20.0 \mathrm{~kg} / \mathrm{m}^{2}\right.$ labeled as underweight, $20<\mathrm{BMI} \leq 25 \mathrm{~kg} / \mathrm{m}^{2}$ labeled as normal weight, $25<\mathrm{BMI} \leq 30$ $\mathrm{kg} / \mathrm{m}^{2}$ labeled as overweight, and $>30.0 \mathrm{~kg} / \mathrm{m}^{2}$ labeled as obese). This BMI classification has been suggested for reproductive endocrinology research [11].

According to WHO guideline, two semen samples about a week apart were taken from each participant by masturbation after 2 - 5 days of abstinence [12]. The samples were assessed by CASA system (sperm class analyzer, V4.0.0, Spain). The result of semen with higher total progressive sperm count was collected in this study. Venous blood samples were withdrawn from each subject for hormone levels analyze. Serum testosterone (T, $\mathrm{nmol} / \mathrm{L}$ ), prolactin (PRL uIU/mL), luteinizing hormone $(\mathrm{LH}, \mathrm{mIu} / \mathrm{mL}$ ), follicle-stimulating hormone (FSH, $\mathrm{mIu} / \mathrm{mL}$ ), and estradiol $\left(\mathrm{E}_{2}, \mathrm{pmol} / \mathrm{L}\right.$ ) levels were estimated by the Chemiluminescence method (Siemens healthcare diagnostics Inc, USA).

\section{Statistical Analysis}

Data were analyzed using SPSS (version 13) statistical software. Mean serum sexual hormone levels and $E_{2} / T$ ratios were compared among BMI groups using one-way analysis of variance. Semen parameters were also compared in the same way. To assess the correlation between BMI and other variables, the spearman correlation analysis was calculated. All the statistical tests were done on a two-tailed basis, and P-value $<0.05$ was considered a statistically significant result.

\section{Results}

Three hundred and ninety males participated in the study. After the subjects were classified into four groups based on BMI, we found that blood pressure increased accompanying with the increase of BMI. There was no significant difference among four groups in any of semen parameters and serum levels of FSH, LH, PRL and $\mathrm{E}_{2}$. Obese and overweight men were found having lower serum $T$ levels and higher $E_{2} / T$ ratio levels than those of normal and underweight men. The clinical characteristics, serum sexual hormone levels and semen characteristics of subjects are shown in Table 1.

Using the spearman correlation analysis, there was no significant correlation between BMI and any of semen parameters, but a significant negative correlation between BMI and serum T levels was found (Table 2). 
Table 1. Semen characteristics and sexual hormone levels compared for males among BMI groups.

\begin{tabular}{|c|c|c|c|c|c|c|c|c|}
\hline & \multicolumn{8}{|c|}{ BMI groups } \\
\hline & \multicolumn{2}{|c|}{$\leq 20$} & \multicolumn{2}{|c|}{$20<\mathrm{BMI} \leq 25$} & \multicolumn{2}{|c|}{$25<\mathrm{BMI} \leq 30$} & \multicolumn{2}{|c|}{$>30$} \\
\hline & \multicolumn{2}{|c|}{$\mathrm{n}=46$} & \multicolumn{2}{|c|}{$\mathrm{n}=231$} & \multicolumn{2}{|c|}{$\mathrm{n}=100$} & \multicolumn{2}{|c|}{$\mathrm{n}=13$} \\
\hline & Mean & SD & Mean & SD & Mean & SD & Mean & SD \\
\hline Age (Years) & 31.43 & 3.47 & 33.08 & 4.92 & 33.56 & 5.78 & 34.62 & 6.47 \\
\hline SBP (mmHg) & $120.64^{\mathrm{d}}$ & 11.70 & $118.96^{\mathrm{cd}}$ & 11.28 & $122.34^{\text {bd }}$ & 11.47 & $129.77^{\mathrm{abc}}$ & 15.04 \\
\hline DBP (mmHg) & $71.40^{\mathrm{d}}$ & 8.73 & $71.45^{\mathrm{cd}}$ & 9.43 & $74.15^{\text {bd }}$ & 9.56 & $81.31^{\mathrm{abc}}$ & 12.53 \\
\hline Semen volume $(\mathrm{mL})$ & 3.45 & 1.49 & 3.09 & 1.31 & 3.53 & 1.49 & 2.72 & 1.32 \\
\hline $\begin{array}{l}\text { Sperm concentration } \\
\qquad\left(10^{6} / \mathrm{mL}\right)\end{array}$ & 59.75 & 42.94 & 65.79 & 43.87 & 63.42 & 43.73 & 69.29 & 48.68 \\
\hline $\begin{array}{l}\text { Total sperm count } \\
\left(10^{6} / \text { ejaculate }\right)\end{array}$ & 206.45 & 191.06 & 203.43 & 158.44 & 222.06 & 186.32 & 179.21 & 164.28 \\
\hline Sperm motility (\%) & 52.53 & 19.59 & 50.08 & 22.63 & 50.78 & 20.95 & 59.12 & 21.24 \\
\hline $\begin{array}{l}\text { Total progressive sperm } \\
\text { count (10\%/ejaculate) }\end{array}$ & 85.35 & 116.87 & 76.91 & 86.74 & 74.23 & 78.95 & 67.92 & 65.65 \\
\hline $\mathrm{FSH}(\mathrm{mIU} / \mathrm{mL})$ & 5.54 & 3.30 & 4.88 & 2.73 & 4.63 & 2.26 & 5.04 & 3.23 \\
\hline $\mathrm{LH}(\mathrm{mIU} / \mathrm{mL})$ & 4.91 & 3.32 & 4.14 & 2.27 & 3.84 & 1.67 & 4.11 & 1.68 \\
\hline PRL (ng/mL) & 190.72 & 93.23 & 197.44 & 109.79 & 207.86 & 155.32 & 200.55 & 107.23 \\
\hline $\mathrm{E}_{2}(\mathrm{pmmol} / \mathrm{L})$ & 172.13 & 87.15 & 151.43 & 70.54 & 150.27 & 70.36 & 197.24 & 78.67 \\
\hline $\mathrm{T}(\mathrm{mmol} / \mathrm{L})$ & $24.04^{\mathrm{bcd}}$ & 10.73 & $19.22^{\mathrm{ac}}$ & 8.12 & $16.36^{\mathrm{ab}}$ & 6.07 & $16.64^{\mathrm{ab}}$ & 11.50 \\
\hline $\mathrm{E}_{2} / \mathrm{T}$ & $7.29^{\mathrm{cd}}$ & 2.85 & $8.53^{\mathrm{cd}}$ & 4.52 & $10.31^{\mathrm{abd}}$ & 5.47 & $17.24^{\mathrm{abc}}$ & 11.56 \\
\hline
\end{tabular}

${ }^{\mathrm{a}}$ Significant difference between this group and underweight group; ${ }^{\mathrm{b}}$ Significant difference between this group and normal weigh group; ${ }^{\mathrm{c}}$ Significant difference between this group and overweight group; ${ }^{\mathrm{d}}$ Significant difference between this group and obese group.

Table 2. Correlation between BMI and different variables.

\begin{tabular}{ccccc}
\hline & SBP $(\mathrm{mmHg})$ & $\mathrm{DBP}(\mathrm{mmHg})$ & $\mathrm{T}(\mathrm{mmol} / \mathrm{L})$ & $\mathrm{E}_{2} / \mathrm{T}$ \\
\hline $\mathrm{r}$ & 0.153 & 0.141 & -0.285 & 0.289 \\
$\mathrm{p}$ & 0.003 & 0.007 & 0.000 & 0.000 \\
\hline
\end{tabular}

Several clinical and hormonal variables were entered in multiple regression analysis to detect relation to sperm concentration and the total sperm count. Only the serum levels of FSH showed significant association with sperm concentration and the total sperm count. These data are shown in Table 3 and Table 4.

\section{Discussion}

The aim of this study was to investigate the impact of BMI on semen parameters and reproductive hormones. When the mean semen parameter values of each BMI group were compared, we did not find significant changes among these groups. This study did not reveal any relationship between BMI and any of semen parameters of the studied population. The results of this study were generally in accordance with some previous studies [8] [9].

It is generally accepted that BMI have association with sexual hormones levels as well as semen quality [6] [7] [13]. Several studies showed a deleterious effect of obesity on semen quality both in normal fertile and subfertile males [14] [15]. However, there are several reports supporting our findings. In one meta-analysis, no relation between BMI and semen parameters was found [16]. It appears that the relationship between BMI and sperm quality has not been clarified. Further study with adequate sample is needed to reach a solid conclusion.

As for the relationship between BMI and sexual hormonal profile, it is already accepted that BMI is associated with alterations in the levels of testosterone and estrogens [17]. Researchers found significant relations between BMI and serum levels of progesterone and $E_{2}$, but BMI were not associated with PRL or LH serum concentrations in a Nigerian study on 120 men [18]. In this study, obese and overweight men were found having lower serum levels of $\mathrm{T}$ and higher levels of $\mathrm{E}_{2} / \mathrm{T}$ ratio than those of normal and underweight men. It was found 
Table 3. Multiple regression to predict sperm concentration.

\begin{tabular}{ccccc}
\hline Model & B & STD. Error & $\mathrm{t}$ & $\mathrm{p}$ \\
\hline (Constant) & 80.5 & 5.428 & 14.829 & 0 \\
FSH & -2.56 & 0.95 & -2.68 & 0.01 \\
\hline
\end{tabular}

Serum FSH levels showed a negative association with sperm concentration $(p=0.01)$.

Table 4. Multiple regression to predict total sperm count.

\begin{tabular}{ccccc}
\hline Model & B & STD. Error & t & p \\
\hline (Constant) & 252.08 & 20.84 & 12.098 & 0 \\
FSH & -7.94 & 3.66 & -2.17 & 0.03 \\
\hline
\end{tabular}

Serum FSH levels showed a negative association with total sperm count $(p=0.03)$.

that there is a significant negative correlation between BMI and serum T levels.

The levels of $E_{2} / T$ ratio in men of obese and overweight group increased significantly compared with those of normal and underweight groups, but the serum $\mathrm{E}_{2}$ levels were compared among groups. Obese man has more adipose tissues than non-obese man's, which containing aromatizing enzyme that covert androgen into estrogen [19]. In obese man, the serum testosterone levels were decreased and then the substrate for conversion might also decrease. That might explain why not the serum $E_{2}$ levels but the levels of $E_{2} / T$ ratio increased along with BMI.

In this study, there was a significant negative correlation of serum FSH levels and sperm concentration. Moreover, serum FSH levels were significantly associated with total sperm count in the multiple regression model. Serum FSH levels of the patients can predict sperm concentration and total number of sperms. Normal function of the gondotrophic axis, especially normal FSH secretion, plays crucial roles in spermatogenesis [20] [21]. Several experimental and clinical studies have demonstrated the importance of FSH in regulating a normal quantitative spermatogenic process in animals and humans [22] [23]. It has also been suggested that high serum FSH levels is intimately related to a decrease of spermatogenesis function.

Because most of patients with total progressive sperm under 5 million were advised to accept ICSI treatment, azoospermia and severe oligozoospermis were not included in this study, therefore limiting the possible generalization of this study to all adult men. In MacDonald AA studies, among men with a normal BMI, oligozoospermia was found in $21.7 \%$ of men, whereas in men with a BMI $>25$, the prevalence of oligozoospermia was 24.4\%. BMI did not seem to significantly affect the prevalence of oligozoospermia [16]. Based on some articles, we think the findings of this study are reliable and valuable in this field. The lower proportion of obesity (3.33\%) also was the limitation of this study. We will increase the sample size and improve the criteria next step.

\section{Conclusion}

In conclusion, this study has not found evidence of an association between increased BMI and semen parameters, but obesity has a negative effect on serum testosterone levels. Population-based studies with larger sample sizes and longitudinal studies are required.

\section{Acknowledgements}

Erhong Zhang thanks Xiaohuan Xing, employee at the department of endocrinology in the People's Hospital of Zhongshan City, for her support in the statistical analysis. This project was supported by funds of Bayer Medicines Co.

\section{References}

[1] Taylor, A. (2003) ABC of Subfertility: Extent of the Problem. British Medical Journal, 327, 434-436. http://dx.doi.org/10.1136/bmj.327.7412.434

[2] Goldman, R.H., Batsis, M., Hacker, M.R., et al. (2014) Outcomes after Intrauterine Insemination Are Independent of Provider Type. American Journal of Obstetrics \& Gynecology, 29, 501-508. http://dx.doi.org/10.1016/j.ajog.2014.05.033 
[3] Pasquali, R., Patton, L. and Gambineri, A. (2007) Obesity and Infertility. Current Opinion in Endocrinology, Diabetes and Obesity, 14, 482-487. http://dx.doi.org/10.1097/MED.0b013e3282f1d6cb

[4] Du Plessis, S.S., Cabler, S., McAlister, D.A., et al. (2010) The Effect of Obesity on Sperm Disorders and Male Infertility. Nature Reviews Urology, 7, 153-161. http://dx.doi.org/10.1038/nrurol.2010.6

[5] Clark, A.M., Thornley, B., Tomlinson, L., et al. (1998) Weight Loss in Obese Infertile Women Results in Improvement in Reproductive Outcome for all Forms of Fertility Treatment. Human Reproduction, 13, 1502-1505. http://dx.doi.org/10.1093/humrep/13.6.1502

[6] Jensen, T.K., Andersson, A.M., Jørgensen, N., et al. (2004) Body Mass Index in Relation to Semen Quality and Reproductive Hormones among 1558 Danish Men. Fertility and Sterility, 82, 863-870. http://dx.doi.org/10.1016/j.fertnstert.2004.03.056

[7] Hammoud, A.O., Gibson, M., Peterson, C.M., et al. (2008) Impact of Male Obesity on Infertility: A Critical Review of the Current Literature. Fertility and Sterility, 90, 897-904. http://dx.doi.org/10.1016/j.fertnstert.2008.08.026

[8] Stewart, T.M., Liu, D.Y., Garrett, C., et al. (2009) Associations between Andrological Measures, Hormones and Semen Quality in Fertile Australian Men: Inverse Relationship between Obesity and Sperm Output. Human Reproduction, 24, 1561-1568. http://dx.doi.org/10.1093/humrep/dep075

[9] Eskandar, M., Al-Asmari, M., Babu Chaduvula, S., et al. (2012) Impact of Male Obesity on Semen Quality and Serum Sex Hormones. Advances in Urology, 2012, Article ID: 407601. http://dx.doi.org/10.1155/2012/407601

[10] Cooper, T.G., Noonan, E., von Eckardstein, S., et al. (2010) World Health Organization Reference Values for Human Semen Characteristics. Human Reproduction Update, 16, 231-245. http://dx.doi.org/10.1093/humupd/dmp048

[11] Fritz, M. and Speroff, L. (2010) Clinical Gynecologic Endocrinology and Infertility. 8th Edition, Lippincott Williams \& Wilkins, Philadelphia.

[12] World Health Organization, Department of Reproductive Health and Research (2010) WHO Laboratory Manual for the Examination and Processing of Human Semen. 5th Edition.

[13] Qin, D., Yuan, W., Zhou, W., et al. (2007) Do Reproductive Hormones Explain the Association between Body Mass Index and Semen Quality? Asian Journal of Andrology, 9, 827-834. http://dx.doi.org/10.1111/j.1745-7262.2007.00268.X

[14] Stewart, T.M., Liu, D.Y., Garrett, C., et al. (2009) Associations between Andrological Measures, Hormones and Semen Quality in Fertile Australian Men: Inverse Relationship between Obesity and Sperm Output. Human Reproduction, 24, 1561-1568. http://dx.doi.org/10.1093/humrep/dep075

[15] Nguyen, R.H., Wilcox, A.J., Skjaerven, R., et al. (2007) Men’s Body Mass Index and Infertility. Human Reproduction, 22, 2488-2493. http://dx.doi.org/10.1093/humrep/dem139

[16] MacDonald, A.A., Herbison, G.P., Showell, M., et al. (2010) The Impact of Body Mass Index on Semen Parameters and Reproductive Hormones in Human Males: A Systematic Review with Meta-Analysis. Human Reproduction Update, 16, 293-311. http://dx.doi.org/10.1093/humupd/dmp047

[17] Pasquali, R. (2006) Obesity and Androgens: Facts and Perspectives. Fertility and Sterility, 85, 1319-1340. http://dx.doi.org/10.1016/j.fertnstert.2005.10.054

[18] Egwurugwu, J.N., Nwafor, A., Chike, C.P., et al. (2011) The Relationship between Body Mass Index, Semen and Sex Hormones in Adult Male. Nigerian Journal of Physiological Sciences, 26, 29-34.

[19] Finkelstein, J.S., Lee, H., Burnett-Bowie, S.A., et al. (2013) Gonadal Steroids and Body Composition, Strength, and Sexual Function in Men. New England Journal of Medicine, 369, 1011-1022. http://dx.doi.org/10.1056/NEJMoa1206168

[20] Pitteloud, N. and Dwyer, A. (2014) Hormonal Control of Spermatogenesis in Men: Therapeutic Aspects in Hypogonadotropichypogonadism. Annales d'Endocrinologie (Paris), 75, 98-100. http://dx.doi.org/10.1016/j.ando.2014.04.002

[21] Sharpe, R.M. (1989) Follicle-Stimulating Hormone and Spermatogenesis in the Adult Male. Journal of Endocrinology, 121, 405-407. http://dx.doi.org/10.1677/joe.0.1210405

[22] Marshall, G.R., Zorub, D.S. and Plant, T.M. (1995) Follicle-Stimulating Hormone Amplifies the Population of Differentiated Spermatogonia in the Hypophysectomized Testosterone-Replaced Adult Rhesus Monkey (Macacamulatta). Endocrinology, 136, 3504-3511.http://dx.doi.org/10.1210/endo.136.8.7628387

[23] Moudgal, N.R., Murthy, G.S., Prasanna Kumar, K.M., et al. (1997) Responsiveness of Human Male Volunteers to Immunization with Ovine Follicle Stimulating Hormone Vaccine: Results of a Pilot Study. Human Reproduction, 12, 457-463. http://dx.doi.org/10.1093/humrep/12.3.457 
Scientific Research Publishing (SCIRP) is one of the largest Open Access journal publishers. It is currently publishing more than 200 open access, online, peer-reviewed journals covering a wide range of academic disciplines. SCIRP serves the worldwide academic communities and contributes to the progress and application of science with its publication.

Other selected journals from SCIRP are listed as below. Submit your manuscript to us via either submit@scirp.org or Online Submission Portal.
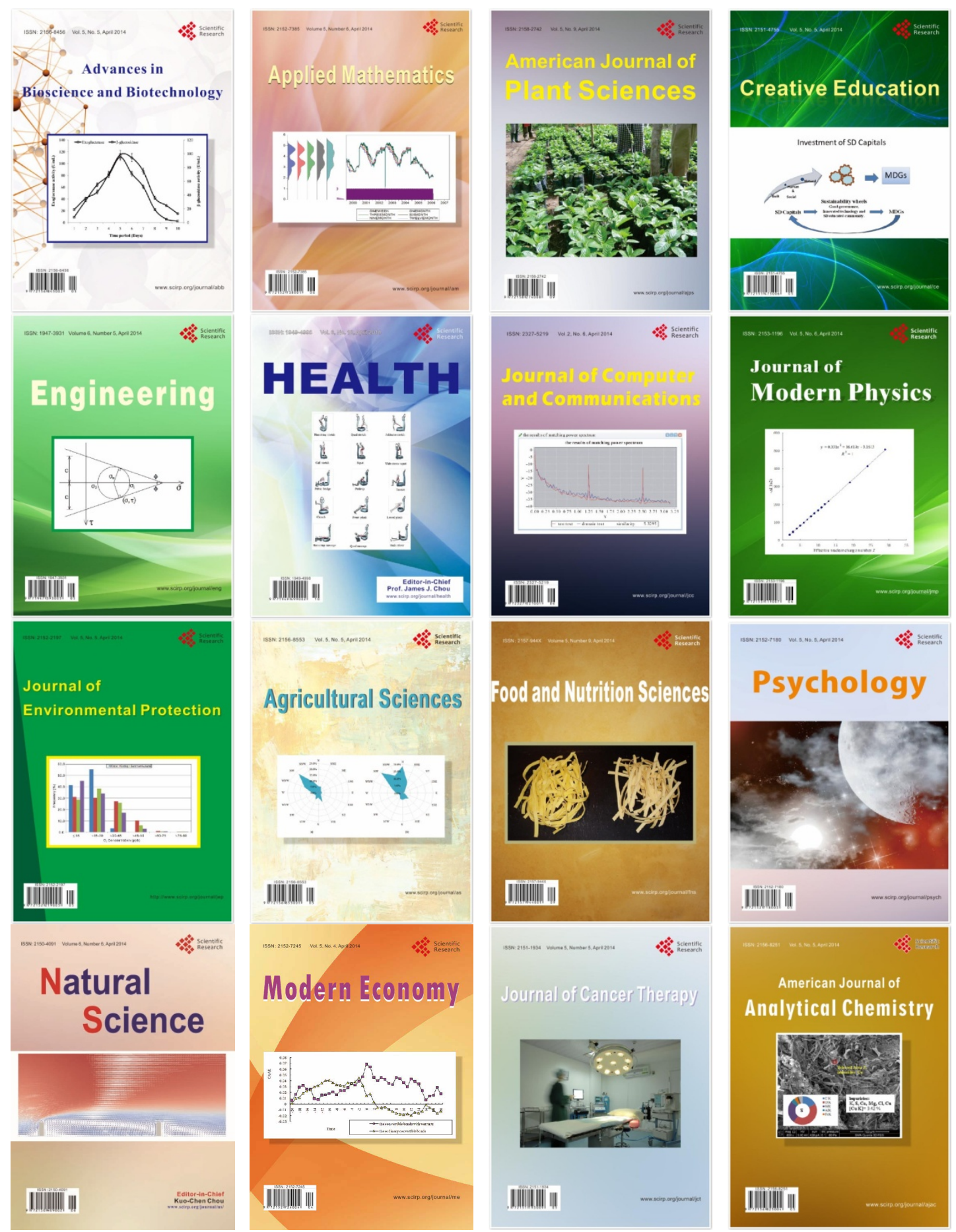